\title{
Using Journals to Assess Non-STEM Student Learning in STEM Courses: A Case Study in Cybersecurity Education
}

\author{
Gary C. Kessler \\ Embry-Riddle Aeronautical \\ University \\ Daytona Beach, Florida, USA \\ Edith Cowan University \\ Perth, AUS \\ gary.kessler@erau.edu
}

\author{
Glenn S. Dardick \\ Embry-Riddle Aeronautical \\ University \\ Daytona Beach, Florida, USA \\ Edith Cowan University \\ Perth, AUS \\ glenn.dardick@erau.edu
}

\author{
Douglas L. Holton \\ Embry-Riddle Aeronautical \\ University \\ Daytona Beach, Florida, USA \\ douglas.holton@erau.edu
}

\begin{abstract}
Embry-Riddle Aeronautical University offers a minor course of study in cybersecurity as an option in our undergraduate Homeland Security program. Since the students are, by and large, social scientists, the focus of the program is to build hyper-awareness of how cybersecurity integrates within their professional aspirations rather than to provide cybersecurity career-level proficiency. Assessing student learning of the technical aspects cannot be performed using traditional tests, as they would not properly measure what the students are learning in a practical sense. Instead, we employ journals and selfreflection to ask the students to express and demonstrate their learning. Although somewhat harder to grade, the journals have huge benefits to the learning environment as well as to actual learning.
\end{abstract}

\section{Introduction}

Embry-Riddle Aeronautical University started an undergraduate Homeland Security degree program in 2006. A five-course, 15-credit Cybersecurity minor was introduced in the fall of 2013 [1]. The discipline of homeland security is closer to the social sciences than it is to the natural sciences, while information security is much more closely aligned to computer science than is comfortable for most social scientists. The challenge is how to optimally assess student learning when teaching a science, technology, engineering, and mathematics (STEM) subject to non-STEM oriented students.

This paper will describe how journals and selfreflection are employed for student learning assessment. Section 2 will provide an overview of the use of journals to assess learning, with a particular focus on use in STEM disciplines. Section 3 will provide an overview of the courses in the cybersecurity minor. Section 4 will discuss why journals were selected as an assessment instrument, and how they fit in to the overall course-grading scheme. Section 5 will discuss how journals are implemented in the courses and some of the initial hurdles in their use. Sections 6 and 7 will provide some results of our experiences, including observations from a formal survey. Finally, Section 8 will offer some conclusions.

\section{Use of Journals to Assess STEM Learning}

Reflective journaling involves students writing about their learning experiences and privately sharing these thoughts with their instructors. This type of activity increases the connection between students and faculty, focuses students' attention on individual learning growth rather than competitive peer comparisons, and increases students' motivation and appreciation for a topic [2]. An important part of this activity is for students to connect the topic to their own life experiences and goals. Journals allow students to assess their own learning; they also aid the instructor in assessing student learning and getting feedback about how to improve learning experiences [3]. It also enhances collaborative and active learning processes, which we employ in the minor [4].

In STEM learning contexts, journals are typically used in conjunction with design projects to reflect on and synthesize what students have learned, as well as document their role in a project. Feedback from the students suggests that reflective writing activities might be an important component for them to gain 
more confidence and self-efficacy in learning about difficult STEM concepts by expressing themselves in a less stressful environment than traditional graded exams and papers. This might be a potentially fruitful area for future research, as we found no literature that specifically addresses non-STEM students in STEM courses. However, there is research that suggests that there are many students, especially women and underrepresented groups, who can succeed in STEM courses but fail to do so for non-cognitive reasons, such as a lack of self-efficacy or confidence [5-7].

Use of journals in the STEM environment, then, is neither a unique nor new approach. Use of journals in STEM courses targeting non-STEM students, however, appears to be a new application with which to assess student learning, although these skills need to be taught and refined [8].

\section{The Cybersecurity Minor}

Kessler and Ramsay [1] describe the cybersecurity minor in detail. The minor was created specifically for Homeland Security students although any student from any major is allowed to take the classes. The course of study is not intended to prepare students for a career in cybersecurity, per se, but to make them acutely aware of cybersecurity issues as they affect the career that they will pursue. Indeed, students studying this minor are much more likely to enter the realm of policy development rather than information systems security design (although several Computer Science students have taken some of the Cybersecurity minor courses in order to broaden their own perspectives).

As an example, many information security buzzwords have entered the vocabulary of managers without full understanding of the vernacular. We are trying to prepare students who have sufficient understanding of the technology so that they can apply it appropriately to their workplace. As an example, if involved in an after-action review of a computer intrusion that was found to exploit a buffer overflow or command injection vulnerability, we would want our students to understand that the solution will more likely involve better programming practices than it would a better firewall.

Briefly, the minor comprises five courses (Figure 1) that start out with many hands-on exercises and transition to a seminar experience, more-or-less stepping up through the cognitive domain of Bloom's taxonomy.

The first course is a 200-level class about computer and network technology. This course discusses the basics of computers, operating systems, and interfaces, local and wide area network technologies, the Internet, and the Transmission Control Protocol/Internet Protocol (TCP/IP) suite. Lectures are supplemented by approximately 10 hands-on exercises where students use both the DOS and Unix command line interface, write a simple Perl program, set up a simple Web page and Web server, build a peer-to-peer network, and employ a packet sniffer.

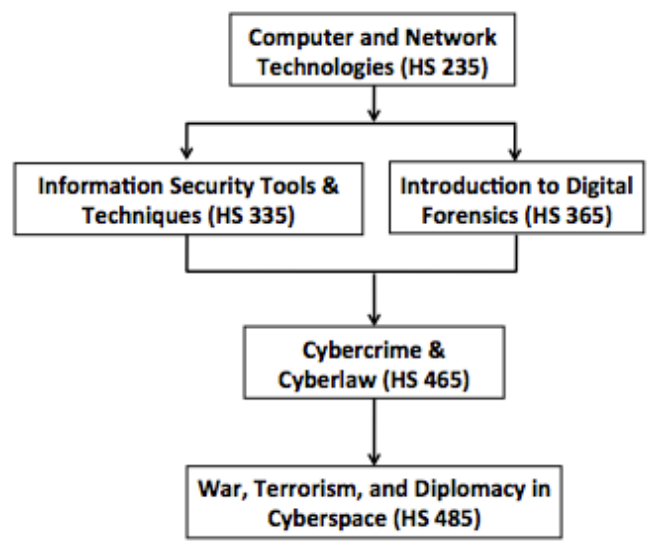

Figure 1. Courses in the Cybersecurity minor.

The next two courses are at the 300-level; one addresses so-called "hacker tools" for offense and defense, and the other covers digital forensics and incident response. These courses also each have about 10 hands-on exercises covering a broad spectrum from performing reconnaissance in order to plan an attack, using port and vulnerability scanners as well as other exploit tools, and building firewalls through examining the structure of a file system, acquiring data in a forensically sound fashion, and analyzing hard drive, mobile phone, and network data.

The fourth course in the minor is a 400-level course that has the transitional role to evolve handson learning to seminar-style learning. The subject matter focuses on cybercrime and cyberlaw, with a few hands-on exercises related to credit cards and cryptography, and assignments for longer student-led class discussions.

The final course is the culminating learning experience in the minor, a seminar-type, 400-level course that explores the major events of the day -war, terrorism, and diplomacy -- in the context of cyberspace. This course brings in many external sources and has the students leading a large portion of the course. The handling of the subject matter is the way in which students demonstrate their learning and how the added technical perspectives have informed their understanding of the subject matter. 
As of the end of the spring 2016 semester, three groups of students have completed the minor. Cohort $\# 1$, composed of a dozen students, went through the minor in the 2013-2015 academic years. Cohort \#2, with 18 students, started in fall 2014 and finished in spring 2016. Cohort \#3, with 16 students, hit the halfway point in the minor in spring 2016.

\section{Learning Theory and Assessment}

Traditional computer courses are a combination of lectures and hands-on exercises, where the exercises are typically taught in a computer laboratory environment. Computer and information security is a subset of computer science and, therefore, requires lectures about technical topics. However, lecture alone is not as effective for student learning. Students cannot gain knowledge of technical topics only by listening; they have to put the lecture material into practice. Hence, the need for hands-on exercises.

When the minor was first proposed, we had neither the budget nor the space to build a computer lab. We also did not want to build such a lab for two reasons. First, if students need to go to a lab in order to do their work, they will generally only go to the lab when they have required work to complete and we wanted students to have more access than a few hours per week. Second, although the minor was initially proposed as a face-to-face program, we envisioned the day when it might be offered online (which it will be, in fact, by the end of 2016).

The students taking the Cybersecurity minor are, by and large, highly motivated but not necessarily possessing much a priori technical expertise with computers. For this population, we decided that problem-based, active learning would best augment the required lecture materials. Students work collaboratively in teams of two or three so that they can help each other and gain even more insights by working with others [9-12].

Hands-on exercises are accomplished using virtual machine (VM) software so that students with any computing platform can access all necessary operating systems and tools. This provides the benefit that teams can do their work at any convenient time and venue. It also provides students with $24 \times 7$ access to the lab environment, which many students use to their advantage. (The design of the VM architecture is the subject of a future paper [13].)

It became clear during course development that assessment of student learning would be a challenge and that traditional examinations, in particular, would be problematic. First, we did not know how to design a test to measure the students' technical knowledge that any of the students would ever pass because they are, in general, not STEM students. Second, since detailed technical knowledge is not the real point of the minor course of study, measuring that would not help us assess student success anyway.

The two primary forms of assessment that we employ in all of the courses in the minor are discussions and journals. An online discussion forum is part of every hands-on exercise and students are required to share their problems, successes, and results with their classmates. Indeed, if a team has a problem, the discussion forum is the first alternative for them to obtain assistance; the collaborative learning extends beyond just the team. Journals are described more in the next section.

\section{Implementing Journals}

In our courses, journals emerged as the primary form of assessing student learning because they provided the students with the best platform with which to demonstrate their grasp and application of the material. In the 200- and 300-level courses -- the ones with the most hands-on exercises -- journals must be submitted every two weeks, with a final journal due at the end of the course; there are a total of eight journals per course. In the 400-level courses, journals are due after the end of each topic module as well as at the end of the course.

Students are told from the very beginning that the journals are in lieu of examinations, so we try to focus their journal assignments on the relevant subject matter. In particular, the assignments ask students to write about what they learned, what topics or ideas resonated with them, what new ideas and perspectives they gained, and how this information will be applied in their lives and careers. (Sometimes, the answer is "none of the above," and we need to hear that, too.)

While initially greeted by the students -- largely because journals appear less intimidating than tests -there were challenges in getting the use of journals running smoothly. The first and biggest hurdle was gaining student trust. The journal assignment, which asks for self-reflection and implies that there are "no wrong answers," is sufficiently vague that it frightens many students. All students have experienced instructors who ask for honest feedback, assure students that there are "no wrong answers," and then assign students a poor grade for not saying what they want to hear. One solution was to tell our students that they would get full credit on the first journal merely for submitting it and getting feedback from 
the instructor that they could apply in subsequent journals, just so that they knew that they were in the right track.

A second hurdle was getting students to articulate their self-reflections more deeply. We found that most students have difficulty with this. First, they do not do a lot of personal writing so writing a journal every two or so weeks is outside of their comfort zone. Second, it takes time for students to open up and share their inner thoughts with an instructor and to trust the instructor not to grade them poorly if they said something "wrong." Finally, most students do not know how they learn and, therefore, often have difficulty identifying what they might have learned in a given block of time -- no one has ever taught them to assess their own learning or asked them to reflect upon it. Indeed, many students' early journals were merely a repeat of the topics that we had covered in class; i.e., a review of what was being taught rather than a review of what they were learning.

A third hurdle is time management. The journals have a due date because we did not want to get one huge journal at the end of the semester. But we stress to students that they can make multiple journal submissions in the given time period and/or take daily notes so that they can prepare their journals as they go along rather than waiting for the last minute to submit the journal. Surprisingly, the majority of lost points are because the journals are submitted late rather than because content is somehow lacking. (In one of our classes, the mantra "The due date is not the do date" somehow emerged.)

We found that most of the trust issues resolve by the middle of the first course, once students better learn the journal process, and student writing improves as they learn to trust the process and instructor. To alleviate some of these issues with student journal writing, we eventually adopted the use of a simple rubric so that grading was less subjective and students had more focused writing goals. Initially, for example, we never had a minimum word count; we added that because there are always students who want to do the least amount of work and it is difficult to non-objectively tell someone that their reflections, while not "wrong," do not go deep enough. We also do not grade the writing, per se; we accept that the writing may be quite informal or grammatically incorrect, and focus on content.

\section{Student Journals -- A Qualitative Review}

At the end of the spring 2016 semester, two cohorts (30 students) had completed the minor and a third cohort (16 students) had completed the first year; the students were primarily Homeland Security majors with just a few in other majors (one in Software Engineering, one in Air Safety, and one in Aerospace Engineering). This yielded more than 1400 journal entries in three academic years.

Anecdotal evidence based upon our observations of student work and journal contents suggests that the use of journals adds a dimension to subject matter understanding and learning that neither the students nor we anticipated. By the end of the course sequence, students are very much in tune with what they are learning, how they are learning, and how this information applies to who they are as a person and what it is they want to do professionally. In some cases, it appears to make them better at understanding what they want to do; in other cases, it has made them reassess their direction.

While there is no research to date that shows a correlation between active, problem-based, and collaborative learning to our model of reflective journaling, our experience suggests that the former informs the latter. Indeed, we found that the most engaging student journals in the early courses were about the hands-on exercises; this is where the students found themselves learning the most. Some research suggests that students need "messy" problems and experiences so that they have something tangible on which to reflect and so that they develop questions that provide them with a reason to learn from future lectures and activities [1415]. The courses in the program climb up Bloom's taxonomy so that later classes have more cognitively challenging activities and fewer hands-on problems, but the students are also more mature, reflective writers by that time.

The excerpts that follow in this section (all from the non-STEM Homeland Security students) speak to several themes that seemed to emerge from a sampling of the journals. Future analysis will systematically analyze and code the responses to possibly discover other, more subtle, trends.

One of the themes that emerged from reviewing student journal entries is that many of the students are incredibly self-aware -- they know where their knowledge or work habits are weak, and they will acknowledge that in a journal (even if they do not immediately fix those deficiencies). They recognize where they are wrong or have made errors. 
We were in fact pleasantly surprised at just how willing students were to admit their fears and concerns about leaving their comfort zone and to acknowledge their own misconceptions. Consider these very first journal entries from three students:

In my opinion, exercise 1 was an eyeopening experience. I learned so much! I went from the bumbling buffoon, to a much less bumbling buffoon! Before exercise 1, I had no idea what a 'command' was, I didn't know what the little windows button on my computer was for, I knew nothing at all. Since then, I feel like my mind has expanded and let in something called "cmd." And I have to admit, I must have spent a solid 20 minutes typing in "color 3d," "color 5f," "colorXY." I feel like for the first time ever, I'm in control of this machine that has consumed so much of my life. Now it's time for sweet revenge. So "color 4c" to you! Yeah that's right, try reading red text on a red background!

HS 235 is my lowest level class but it seems to provide me with the biggest challenge. I feel as if I am completely computer illiterate. Everytime we are in class, I keep my notebook open and write down words from the lecture that I do not understand or that I am unfamiliar with its meaning. Later on in the day I find myself researching the meanings. This process is actually really helpful in gaining a better uderstanding of computers and how they work. I have made much progress by this method and by reviewing the powerpoints... Furthermore, my other classmates have been a great resources. When I was having troubles understanding and working on VirtualBox at least three other people volunteered to help me. I feel that I still have so much to learn but the combination of [the instructor], the discussion board, the powerpoints, other classmates, and google are really helping.

As we do more and more practical exercises in class and at home I am becoming more and more comfortable. However, I still feel that in any practical application I would be totally lost. I sometimes struggle to grasp even the simpler even the simpler concepts. To be quite honest I often feel totally outstripped in class. I hope that as we do more and more I will understand more and more. I am particularly interested in trying my hand at actually cracking someone else's system when they don't want me in it. So when I find holes to exploit I will know what holes to fill when I need to protect a system

Another theme that emerged was that, as time progresses, the students grow more knowledgable, are able to draw better linkages between topics, and demonstrate that through their journals:

I loved going through the exercises in this course... After researching the attack on HBGary, I realized that we covered the majority of Anonymous's attack techniques and vectors. It definitely shows that implementing and enforcing policies and procedures is crucial to the security of a company's cyber space. One thing I found particulary interesting was how the hacker community and security community use the same resources and tools to accomplish two vastly different goals. Between the publishing of zero-day vulnerabilities as well as numerous hacker tools easily available, the two compete with nearly identical resources.

A third theme was that the students, in general, recognize the growth that they have achieved when they look back at the program in toto, such as these comments from two students in the final course of the minor:

When I decided to join the cyber minor I was extremely nervous and extremely uncomfortable with my decision. Since then I have seen a lot of growth. For example, out of fear of eternally ruining my computer with one wrong click, I remember immediately asking for help on the first few exercises. However, after several exercises, I got a little more comfortable with messing around with my computer and researching online to resolve problems. I have come to enjoy the different challenges and asking for help is almost a last resort (depending on the situation).

At the beginning of this minor I thought the material was over my head, and it was probably not for me. Today, I thank [the instructor] for telling me then to try and stay in the class. I have learned so much about 
myself and cybersecurity. I have the confidence now to teach my family, friends and future co-workers basics and more of this class. My critical thinking has become a lot better with this minor. Having to read documents and come up with my own ideas helped me to think outside the box, and put all my thoughts in writing. The journals I think were the best way for you to grade us. It gives us the chance to express ourselves freely about a particular subject without being criticized on how right or wrong we are.

And, incredibly, sometimes students make errors on purpose to further learn what they might discover:

This course started with a new system, which provides two virtual machines, windows and kali. I liked this idea because it is better to have it this way rather than previous courses where we had to do all the work on our personal PCs. This way we can be less intimidated to try new stuff as oppose of what happens when you try something on your own personal PC (not that I would intentionally break virtual machines), but I think that people fear what they do not know, so it is better to experiment new tools on virtual machines.

One of the early hands-on exercises is for students to perform a series of steps using the DOS command line interface (CLI). Those same steps are then repeated using the Unix CLI. The point of the exercises is to show the students that Unix, which is unfamiliar to most of them, is functionally similar to Windows. After performing the Unix exercise, one student team in Cohort \#1 entered Unix commands on the Windows CLI. They knew that this should not work but they elected to try it to see what it would look like when it failed, rather than merely assuming that it would not work. Over time, more students tried more things just to see what would happen. We believe that one reason that students did this was because they were not being graded on what they did right but on what they learned; another reason was that they had their lab software available with them 24 hours a day via the VMs so were never far from a potential experiment.

One student is so self-aware of their learning process that the journals are incredibly detailed -- and long. Rather than merely report on what had been learned, the entire journey was described. The student's step-by-step learning, inquisitiveness, and results are all on the page for the instructor to see.

One initially unexpected result of the use of journals is how much the learning environment in the classroom improved with the absence of traditional tests. Once the "test anxiety" factor was removed, students were no longer focused on passing the exam but, rather, on being prepared for the hands-on exercises. Students focused on the materials that they found most interesting and personally relevant, and on getting material for the next journal. We realized that students spend a lot of energy trying to prepare for the test, even in courses where the test is not the primary factor in the course grade. In the first three cohorts, only one student made a class evaluation comment that they would have preferred a traditional test on facts rather than the journals.

Another recurring theme of the journals is the expression by many of the students about how much they are getting out of the program even though it is technically focused, and they thought that they were not "technical enough." The whole point of the minor program was to prepare students to understand the technical details or, at least, the ramifications, behind discussions surrounding technology. Consider the controversy in early 2016 between the FBI and Apple $[16,17]$. This was a much more complex conversation than the media and most pundits made it out to be, and the cybersecurity students had a very good handle on the arguments because they have had an introduction to encryption, mobile devices, operating systems, software, privacy, law and policy, the U.S. Constitution, homeland security, and more. Indeed, the conversations and debates in our classrooms were much more informed than those that took place in general public discourse and even the students were (pleasantly) surprised with how many of the subtleties escaped the media.

\section{Students' Response to Journals}

At the end of the spring 2016 semester, we conducted a formal survey of two classes of cybersecurity students -- second and third cohorts -in order to supplement the more anecdotal information previously obtained. The survey included five open-ended questions about various aspects of the journaling experience. In all, 27 students (79\%) responded to the survey. Thirteen of the respondents were in Cohort \#2, thus completing the Cybersecurity minor and having taken four of the courses from this paper's first author and one course from the second author. Fourteen of the respondents were in Cohort \#3 and mid-way through the minor, having taken 
both courses from the second author. Three survey questions specifically asked the students to reflect on the journal experience and were particularly helpful in our understanding of the impact of journals on student learning, and these are discussed below.

The first question asked students to reflect on what they had learned about themselves through the journaling process (Table 1). The majority of the short answers in both classes noted that the journals resulted in better learning of the materials, largely because they concentrated on the material that resonated with themselves rather than focus on learning for a test. It is noteworthy that this theme was overwhelming in Cohort 3, while in Cohort 2 -students who had had three more courses than those in Cohort 3 -- students were split between better learning and an ability to better express their ideas and what they had learned. This could possibly suggest that students in the first year are more focused on the different way of learning and it is not until the second year that they expand to recognize how they express themselves in a new, different way. Indeed, one person in Cohort 2 did suggest that he/she preferred traditional tests to the journals, demonstrating that this mode of assessment is not for every student.

Table 1. What did you learn about yourself?

\begin{tabular}{|l|c|c|c|c|}
\hline & $\begin{array}{c}\text { Prefer } \\
\text { Tests }\end{array}$ & Nothing & $\begin{array}{c}\text { Better } \\
\text { Express. }\end{array}$ & $\begin{array}{c}\text { Better } \\
\text { Learning }\end{array}$ \\
\hline Cohort 2 & 1 & 2 & 5 & 7 \\
\hline Cohort 3 & 0 & 2 & 1 & 11 \\
\hline
\end{tabular}

Table 2. What did you enjoy the most?

\begin{tabular}{|l|c|c|c|c|}
\hline & $\begin{array}{c}\text { No } \\
\text { Tests }\end{array}$ & $\begin{array}{c}\text { Freedom } \\
\text { Express. }\end{array}$ & Openness & $\begin{array}{c}\text { Better } \\
\text { Learning }\end{array}$ \\
\hline Cohort 2 & 2 & 8 & 3 & 2 \\
\hline Cohort 3 & 3 & 0 & 3 & 7 \\
\hline
\end{tabular}

The second question asked students what they enjoyed about the journal experience (Table 2). Answers again varied amongst the students and with different emphasis from the different cohorts. The majority of comments from the Cohort 2 students were to the effect that they enjoyed the freedom of expression that journals allowed, possibly because grading was primarily on content rather than format. Students liked that they could comment on any aspect of the course, the material, what they learned, and its relevance, and they did not have to worry about being "wrong." The majority of comments from Cohort 3 addressed that they enjoyed the "learning more" aspect that the journals allowed them to demonstrate. This is, in our opinion, an important result. Not only do the students recognize that they are learning more, but they like the fact that they are learning more. By the second year writing journals, they see a difference and their appreciation now seems to focus on the freedom that they have in the journals.

Table 3. What did you enjoy the least?

\begin{tabular}{|l|c|c|c|c|}
\hline & Nothing & $\begin{array}{c}\text { Time/ } \\
\text { Quantity }\end{array}$ & $\begin{array}{c}\text { What } \\
\text { To } \\
\text { Write }\end{array}$ & $\begin{array}{c}\text { Dislike } \\
\text { Writing }\end{array}$ \\
\hline Cohort 2 & 4 & 2 & 4 & 1 \\
\hline Cohort 3 & 1 & 4 & 3 & 4 \\
\hline
\end{tabular}

The third survey question asked students what they enjoyed the least about the journaling process. There seemed to be general consensus in both cohorts that one thing they disliked was not always knowing what to write about. Some admitted that they felt that they should know more than they did. Interestingly, some of the students mentioned that they did not remember all of the things to write about at the end of the journal interval without remembering that we frequently remind them of the strategy of keeping notes of what to write about or, even better, post multiple times during the journal interval (something that is explicitly allowed in all of the journal assignments). Cohort 2 also had a large percentage that reported that there was nothing about the journal experience that they did not enjoy. Members of Cohort 3 also focused on two other issues. First, they felt that journals were too time-consuming, in one case requiring more time than preparing for tests (it is unclear whether this student spent copious amount of time writing their journal or scant time preparing for exams). Second, several members of this cohort noted that they did not enjoy the journals simply because they did not like to write.

\begin{tabular}{|l|l|l|l|l|l|}
\hline \multicolumn{2}{|c|}{ Criteria } & \multicolumn{2}{|c|}{ Ratings } & \multicolumn{1}{|c|}{ Pts } \\
\hline $\begin{array}{l}\text { Critical Thinking/Development of Ideas } \\
\text { view longer description }\end{array}$ & $\begin{array}{l}\text { Excellent } \\
5 \text { pts }\end{array}$ & $\begin{array}{l}\text { Satisfactory } \\
3 \text { pts }\end{array}$ & $\begin{array}{l}\text { Poor } \\
1 \text { pts }\end{array}$ & 5 pts \\
\hline $\begin{array}{l}\text { Clear writing \& thought process } \\
\text { view longer description }\end{array}$ & $\begin{array}{l}\text { Excellent } \\
5 \text { pts }\end{array}$ & $\begin{array}{l}\text { Satisfactory } \\
3 \text { pts }\end{array}$ & $\begin{array}{l}\text { Poor } \\
1 \text { pts }\end{array}$ & 5 pts \\
\hline $\begin{array}{l}\text { Thoughtful, reflective } \\
\text { view longer description }\end{array}$ & $\begin{array}{l}\text { Excellent } \\
5 \text { pts }\end{array}$ & $\begin{array}{l}\text { Satisfactory } \\
3 \text { pts }\end{array}$ & $\begin{array}{l}\text { Poor } \\
1 \text { pts }\end{array}$ & 5 pts \\
\hline $\begin{array}{l}\text { Relevance to topic } \\
\text { view longer description }\end{array}$ & $\begin{array}{l}\text { Excellent } \\
5 \text { pts }\end{array}$ & $\begin{array}{l}\text { Satsfactory } \\
3 \text { pts }\end{array}$ & $\begin{array}{l}\text { Poor } \\
1 \text { pts }\end{array}$ & 5 pts \\
\hline $\begin{array}{l}\text { Responsiveness to feedback/Progress } \\
\text { view longer description }\end{array}$ & $\begin{array}{l}\text { Excellent } \\
5 \text { pts }\end{array}$ & $\begin{array}{l}\text { Satisfactory } \\
3 \text { pts }\end{array}$ & $\begin{array}{l}\text { Poor } \\
1 \text { pts }\end{array}$ & 5 pts \\
\hline & & \multicolumn{2}{|l|}{ Total Points: 25} \\
\hline
\end{tabular}

Figure 2. Grading rubric.

As with any student assessment instrument, there are those students who want to do the minimum necessary to get by and those that will embrace the opportunity. While our student population includes a large number of the latter, we also have some of the former. In order to provide some structure to the journal exercise, we introduced a rubric (Figure 2) at the beginning of the spring 2016 semester, to help guide the students to be able to meet expectations. 
The survey provided some interesting insights with respect to the rubric. Several of the students -- all of whom self-identified as liking the freestyle of the journal -- noted that they were initially concerned that the rubric would constrain their writing style but they soon realized that the rubric was not really intended for that purpose and was not directed at them. A couple of other students said that they did not like having a minimum word count. Most understood that the rubric provided a framework for both writing and grading, and seemed to accept the added structure.

\section{Conclusions}

Overall, we have observed predominately positive results from using journals to assess student learning in the courses in the Cybersecurity minor. Teaching STEM subject matter to non-STEM students is somewhat out of the ordinary; thus, using an out-ofthe ordinary assessment method just seems to make sense. The first two authors of this paper have taught all of the courses, hence we have been able to see first-hand the growth in the students, both in subject matter knowledge and as learners.

An advantage that we have with the minor is that the scheduling and prerequisite structure means that most of the students are together in a cohort over two years; the first course is offered in the fall semester and students step through the next four courses during the next three terms. By the end of the first year, there is good class chemistry -- and trust -between the students (individually and as a group) and the instructor, leading to an improved classroom and learning experience that is often noted in the journals. In addition, the students get more comfortable in their journals and their writing gets better; they are more fluid, more reflective, deeper, and introspective. While it takes longer to read and respond to the journals than to a traditional test, it is also far more rewarding to read the words of the students. Our observations seem to be largely supported by the student comments on the survey.

We have shared our positive results with our colleagues (e.g., see [18]) both at our campus and university, and with other colleges and universities, and many instructors are considering using this more intimate form of assessment. It is certainly not well suited to all subject matter at all levels, but it clearly can work in a multidisciplinary or cross-disciplinary environment with appropriately reflective students.

\section{References}

[1] Kessler, G.C., and J.D. Ramsay, "A Proposed Curriculum in Cybersecurity Education Targeting Homeland Security Students", Proceedings of the 47th Hawaii International Conference on System Science (HICSS-47), 2014, 4932-4937.

[2] Rosenberg, R.C., and J. Sticklen, "Guided reflection", ASEE Annual Conference \& Exposition, 2011. https://peer.asee.org/guided-reflection

[3] Angelo, T.A., and K.P. Cross, Classroom Assessment Techniques, Jossey-Bass, San Francisco, 1993.

[4] Dehler, G.E., and M.A. Welsh, "Against SpoonFeeding. For Learning. Reflections on Students' Claims to Knowledge", Journal of Management Education, 2014 December, 38(6), 875-893.

[5] Ellis J, B.K. Fosdick, and C. Rasmussen, "Women 1.5 Times More Likely to Leave STEM Pipeline after Calculus Compared to Men: Lack of Mathematical Confidence a Potential Culprit", PLoS ONE, 2016, 11(7), e0157447, doi:10.1371/journal.pone.0157447

[6] Estrada, M., M. Burnett, A.G. Campbell, P.B. Campbell, W.F. Denetclaw, C.G. Gutiérrez, et al., "Improving Underrepresented Minority Student Persistence in STEM", CBE-Life Sciences Education, 2016, 15(3). http://www.lifescied.org/content/15/3/es5.full.pdf + html

[7] Tibbetts, Y., J.M. Harackiewicz, S.J. Priniski, and E.A. Canning, "Broadening Participation in the Life Sciences with Social-Psychological Interventions", CBE-Life Sciences Education, 2016, 15(3). http://www.lifescied.org /content/15/3/es4.full.pdf + html

[8] Pavlovich, K., E. Collins, and G. Jones, "Developing Students' Skills in Reflective Practice: Design and Assessment", Journal of Management Education, 2009 February, 33(1), 37-58.

[9] Donaldson, J.A., and N.N. Knupfer, "Education, learning, and technology", In P.L. Rogers, Designing Instruction for Technology-Enhanced Learning (pp. 19-54), Idea Group Publishing, Hershey, PA, 2002.

[10] Hans, V.P., "Integrating active learning and the use of technology in legal studies courses", In B.J. Duch, S.E. Groh, \& D.E. Allen (Eds.), The Power of Problem-Based Learning (pp. 141-148), Stylus Publishing, Sterling, VA, 2001.

[11] Kessler, G.C., "Experiences and methodologies teaching hands-on cyberforensics skills online", Proceedings of CFET 2007: 1st International Conference on Cybercrime Forensics Education and Training, 2007. http://www.garykessler.net/library/CFET2007_online_lab exercises.pdf 
[12] Meyers, C., and T.B., Promoting Active Learning: Strategies for the College Classroom. Jossey-Bass, San Francisco, 1993.

[13] Dardick, G.S., and G.C. Kessler, "The Design of a VM Server to Support Cybersecurity Education", (in preparation).

[14] Schwartz, D.L., and J.D. Bransford, "A Time for Telling", Cognition and Instruction, 1998, 16(4), 475-522.

[15] Kapur, M. "Productive Failure", Cognition and Instruction, 2008, 26(3), 379-424.

[16] Kharpal, A., "Apple vs FBI: All you need to know", CNBC, 2016 March 29. http://www.cnbc.com/2016/03/29 /apple-vs-fbi-all-you-need-to-know.html

[17] Metz, C., "Forget Apple vs. the FBI: WhatsApp Just Switched on Encryption for a Billion People", Wired, 2016 April 5. http://www.wired.com/2016/04/forget-apple-vsfbi-whatsapp-just-switched-encryption-billion-people/

[18] Kessler, G.C., "Gary Kessler on Student Journaling", Center for Teaching and Learning Excellence, EmbryRiddle Aeronautical University, 2015. https://www.youtube.com/watch?v=5I9LI9zdOW8 